\title{
Asymmetry in active complexes of FLP recombinase
}

\author{
Xiao-hong Qian and Michael M. Cox ${ }^{1}$ \\ Department of Biochemistry, University of Wisconsin-Madison, Madison, Wisconsin 53706 USA
}

\begin{abstract}
The FLP recombinase promotes a site-specific recombination reaction in the $2 \mu$ plasmid of yeast. The protein-DNA complex that carries out the reaction is asymmetric. Three FLP monomers bound to specific FLP-recognition sequences are required to efficiently carry out one set of reciprocal DNA cleavage and strand exchange events on a Holliday junction substrate. If a fourth monomer plays an auxiliary role in the reaction, it is bound without sequence specificity. The data suggest a modified model for cleavage of DNA in trans by the FLP recombinase that might help reconcile some seemingly conflicting results obtained with integrase class recombinases.
\end{abstract}

[Key Words: Yeast; FLP recombinase; Holliday structures; DNA cleavage; $2 \mu$ plasmid]

Received January 9, 1995; revised version accepted June 29, 1995.

The FLP protein is a site-specific recombinase that is encoded by the $2 \mu$ plasmid of Saccharomyces cerevisiae (Cox 1989; Sadowski 1993; Jayaram 1994). Two FLP recombination target sequences (FRTs) are present on the plasmid, and recombination between them during replication results in amplification of plasmid copy number. The minimal FRT site consists of two 13-bp inverted repeats separated by an 8-bp spacer region (Fig. 1). A third repeat present in a wild-type FRT has no apparent effect on recombination efficiency. Each FRT site has two 12bp binding sites for FLP protein, spanning the outer base pair of the spacer sequence and $11 \mathrm{bp}$ of the neighboring repeat on either side.

FLP is an integrase-class recombinase, exhibiting a mechanistic and structural relationship to a family of $>30$ proteins that includes the bacteriophage $\lambda$ integrase (Argos et al. 1986; Abremski and Hoess 1992; Stark et al. 1992). The family can be subdivided into two types (Craig 1988; Landy 1993; Sadowski 1993). Type I enzymes, including FLP and the Cre recombinase of bacteriophage $\mathrm{P} 1$, have a single DNA-binding domain and are targeted to relatively simple recombination sites. The $\lambda$ integrase is a type II enzyme. It has two DNA-binding domains with different sequence specificity. Its recombination site in the DNA can be much more complex, and recombination is facilitated by several other proteins.

Recombination promoted by enzymes of the integrase family, regardless of type, proceeds via a similar mechanism. A sequential pair of reciprocal strand exchanges generates, and then resolves, a Holliday intermediate (or, alternatively, a $x$ structure). The first strand exchange is initiated when each recombining site is cleaved at one

${ }^{1}$ Corresponding author. boundary of the spacer region, replacing the phosphodiester bond with a $3^{\prime}$-phosphotyrosine covalent adduct via trans-esterification. The liberated 5 '-hydroxyl ends act as nucleophiles in a second set of trans-esterification reactions to complete the strand exchange and generate the Holliday junction. A similar set of reactions at the other end of the spacer region resolves the Holliday junction to create recombined products. The nucleophile in the initial cleavage step is a tyrosine residue [Tyr-343 in FLP; (Evans et al. 1990)] that is highly conserved in the integrase family. One His and two Arg residues are also conserved and play role in activating the scissile phosphodiester bond for cleavage (Pan and Sadowski 1992; Kimball et al. 1993).

In the FLP system, mutations in the Arg-His-Arg (RHR) triad do not complement each other, but enzymes with these mutations are complemented in vitro by enzymes with a mutation in Tyr-343 (Chen et al. 1992). This and related observations led Jayaram and colleagues to propose that DNA cleavage by FLP recombinase was mediated by a composite active site. The RHR residues were contributed by the FLP monomer bound to the FLP recognition sequence adjacent to the scissile phosphodiester bond, whereas the tyrosine was contributed by a different FLP monomer (Jayaram 1994). Because the nucleophylic tyrosine comes from an FLP monomer not bound to the adjacent FLP recognition sequence, cleavage is said to occur in trans. When one factors in both of the recombination sites undergoing a reaction, with up to four FLP monomers taking part, there are actually three different possibilities for cleavage in trans (Fig. 2AC). These are trans-horizontal (cleavage across the spacer by the other FLP monomer bound to a single FRT), transdiagonal, and trans-vertical. The last of these utilizes only two FLP monomers to form the two composite active sites needed for reciprocal strand exchange, whereas 


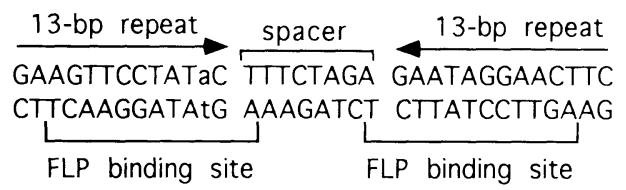

Figure 1. The minimal FRT sequence.

the other two models require four monomers to form the same two active sites. The remaining alternative, in which a monomer cleaves the phosphodiester bond adjacent to where it is bound, is called cis cleavage. All of these models can be drawn with protein monomers related by a twofold rotational axis.

For FLP, the original results leading to the proposal of cleavage in trans by FLP recombinase (Chen et al. 1992) were consistent with either the trans-horizontal or the trans-diagonal mode, with some evidence favoring the latter possibility. Although the trans-diagonal mode was emphasized in a number of subsequent reports, more recent results from the Jayaram group strongly favor the trans-horizontal mode (Lee et al. 1994). The results have been quite different for the $\lambda$ integrase. Although one study demonstrated a mutational complementation that supported trans cleavage (Han et al. 1993), more recent results strongly favor cis cleavage (Nunes-Düby et al. 1994). The sometimes conflicting results have led to some speculation about a possible duality in the reaction mechanism of integrase-class recombinases.

In the FLP system, these mechanisms are manifested not only in DNA cleavage patterns but also in the formation of highly stable protein complexes. When a modified FRT site (with a symmetrical spacer sequence) is cut symmetrically in the spacer region to create a halfsite, recombination does not occur. However, FLP binds to half-sites and links multiple sites together in noncovalent head-to-head complexes that have a lifetime on the order of hours (Qian et al. 1990). Some of the halfsites are cleaved in these complexes. The dimeric species is most prevalent, but a trimeric species is also prominent. Tetramers are observed but at levels that nearly defy detection (Qian et al. 1990). There is also evidence that the $\lambda$ integrase functions as a trimeric complex (Franz and Landy 1990; Kho and Landy 1994).

We have re-examined the extent of DNA cleavage in the trimeric half-site complexes in a more rigorous way. This led to a series of experiments suggesting that three FLP protein monomers combine to form two composite active sites for cleavage, whereas a fourth FLP monomer is either absent or only has an auxiliary function. The results may reflect novel aspects of the inherent asymmetry in FLP complexes that are inconsistent with the models shown in Figure 2, A-C.

\section{Results}

\section{Experimental design}

The experiments described below were designed to evaluate the numbers of FLP monomers present in FLP com- plexes that carry out DNA cleavage and/or strand exchange during site-specific recombination. The work focuses on the stable noncovalent FLP complexes with half-FRT sites observed by Qian et al. (1990) and on Holliday junction resolution experiments modeled after those of Sadowski and colleagues (Dixon and Sadowski 1993). Numbers of FLP monomers in complexes are inferred from the number of FLP-binding sites present in the DNA substrates, supplemented by data from gel retardation experiments.

Extent of DNA cleavage in FLP protein complexes observed with half-FRT sites

When FLP recombinase is incubated with half-FRT site substrates, head-to-head dimeric and trimeric species are formed that are highly stable. These species were identified and characterized in detail in a previous report (Qian et al. 1990). Half-FRT sites can be end labeled so that the label is removed if the DNA is cleaved by FLP recombinase. Previously, we estimated the extent of cleavage in the complexes by comparing the fraction of DNA in each species (determined by densitometric scans of negatives of gel photographs) to the fraction of label in each species (determined by scintillation counting of the isolated DNA species from the same gel). Although these methods had several potential sources of error, we estimated that $50 \% \pm 5 \%$ of the sites had been cleaved in the dimers. The data for the trimers were less reliable, indicating that $61 \%-77 \%$ of the half-sites were cleaved. The results were the same after either 5 or 30 min of reaction, so that the extent of cleavage appeared to reflect a reac-

(1). Cis-cleavage:

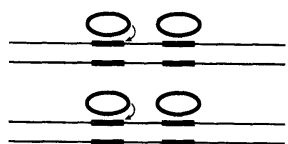

(II). Trans-cleavage:
A horizontal

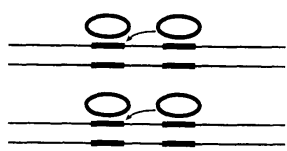

C vertical

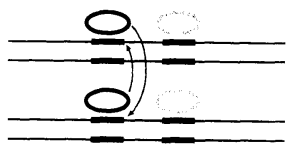

B diagonal

D Asymmetrical

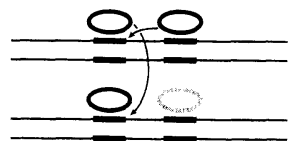

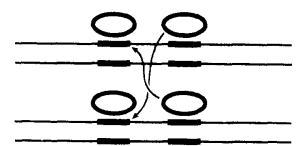

Figure 2. Models for DNA cleavage by FLP recombinase. Arrows indicate the tyrosine nucleophiles. Heavy bars indicate the FLP protein-binding sites. FLP recombinases (light shading) are not directly involved in cleavage reactions. The schemes are drawn with the two FRT sites in parallel alignment. 
tion endpoint regardless of the time at which the determination was made.

We determined that more accurate numbers might be informative and developed a procedure with a better internal standard. The XbaI-cut half-site DNA substrate (Fig. 3) was labeled uniformly at both ends. When this molecule is cut by a second restriction enzyme (PstI) to generate two pieces, both of the resulting gel bands have the same amount of label, and the fragment lacking the half-site $(0.8 \mathrm{kbp})$ becomes an internal standard with which to evaluate loss of label from the half-site fragment $(2.0 \mathrm{kbp})$. After reaction to form complexes, the dimeric and trimeric species were cut out of gels. The DNA in each band was then isolated, treated with PstI, and run on another gel (Fig. 4). The gel was dried, and the labeled bands cut out and evaluated by scintillation counting. Loss of label at the half-site end relative to the other end quantitatively reflects the extent of DNA cleavage in the complex.

The data are summarized in Figure 4D. In the dimeric complexes, $50 \%$ of the half-sites were cleaved, confirming the earlier result. In the trimeric complexes, two of three half-sites were cleaved. The complexes analyzed in Figure 4D were isolated after $10 \mathrm{~min}$ of reaction. These numbers were highly reproducible. Although a variety of interpretations are possible, the simplest is that three FLP monomers bound tightly to DNA are required for two cleavage events.

\section{$\chi$-Structure resolution}

Additional experiments were carried out to determine whether the 3:2 monomer/cleavage ratio could be substantiated in other FLP reactions. The $x$-structure molecules, either isolated from FLP reactions or made from synthetic oligonucleotides, can be resolved efficiently by FLP protein (Dixon and Sadowski 1993). In this study we used synthetic $\chi$ structures as DNA substrates. The wild-type $\chi$ structure contains four FLP-binding sites. The flanking sequences are nonhomologous and stabilize the $x$ structure (see Materials and methods). The arms also differ in length so that the products reflect the location of the cleavage and strand exchange by which they are generated. The $\chi$ molecules were labeled at the $5^{\prime}$ end of one oligonucleotide (the 80-mer, Fig. 5). Resolution of the wild-type $\chi$ molecule should generate two

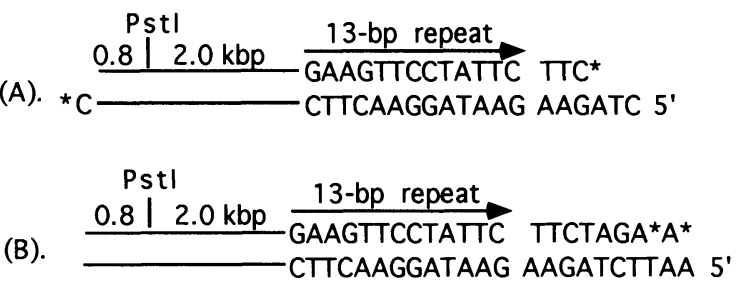

Figure 3. Half-FRT sites. $(A) X b a I-c u t$ and $\left[\alpha^{-32} \mathrm{P}\right] \mathrm{dCTP}$-labeled pXHQ01 half-site. Restriction site PstI divides the linear molecule into 0.8 - and 2.0-kbp segments. $(B)$ EcoRI-cut and $\left[\alpha-{ }^{32} \mathrm{P}\right] \mathrm{dATP}-\mathrm{labeled} \mathrm{pXHQ01}$ half-site.

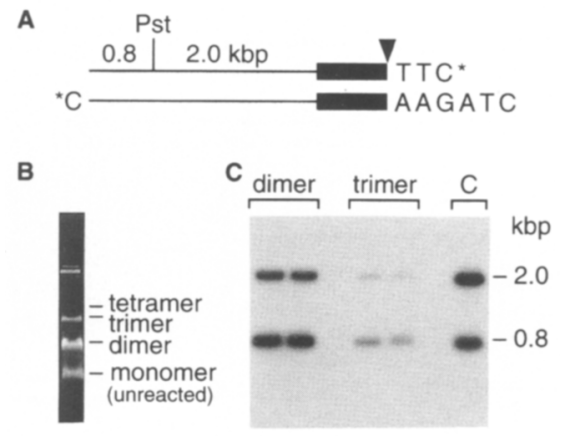

D Label Remaining:

\begin{tabular}{|rr|c|c|}
\cline { 2 - 4 } \multicolumn{1}{c|}{} & dimer(\%) & trimer(\%) \\
\hline exp. & 1 & 55 & 30 \\
& 2 & 51 & 35 \\
& 3 & 53 & 33 \\
& 4 & 51 & 32 \\
5 & 51 & 37 \\
\hline average & $52 \pm 3 \%$ & $33 \pm 4 \%$ \\
\hline
\end{tabular}

Figure 4. Quantitation of extent of DNA cleavage in dimeric and trimeric half-site complexes. $(A)$ DNA substrate used in the reaction. Half-FRT site plasmid pXHQOI was cut with $X b a I$ and labeled at both $3^{\prime}$ ends with $\left[\alpha^{-32} \mathrm{P}\right] \mathrm{dCTP}$. The inverted arrowhead indicates cleavage site. Heavy bars represent FLP-binding site (not to scale). $(B)$ Complex formation in a reaction of FLP protein with half-sites. The reaction was carried out with $5.4 \mathrm{nM}$ of the labeled half-site shown in $A$ and $43 \mathrm{nM}$ FLP protein. Reaction aliquots were subjected to nondenaturing, low-meltingtemperature agarose gel electrophoresis as in Qian et al. (1990). Some experiments summarized in $C$ and $D$ were carried out with twice as much ( $85 \mathrm{nM})$ FLP protein. The results were indistinguishable from those carried out with $43 \mathrm{~nm}$ FLP. (C) Quantitation of label at two ends of half-site. Trimeric complex isolated from a gel such as in $B$ were treated with PstI restriction digestion and subjected to gel electrophoresis and autoradiography. Radioactivity of each fragment was quantitated as described in Material and methods. Lane C contains a PstI-cut substrate as internal control. ( $D$ ) Label remaining at the half-site end in dimer or trimer half-site complexes. Data are expressed as the label remaining in the 2.0 -kbp fragment divided by the label in the 0.8 -kbp fragment. Data represent five separate experiments.

different products (Fig. 5), separable by gel electrophoresis.

Additional $\chi$ structures were generated that lacked one or more of the FLP-binding sites. The altered binding sites were designed to represent the least optimal site possible, with 10 of 13 positions changed to sequences that have the most adverse effect on binding as defined previously (Senecoff et al. 1988). The $x$ structures with one, two, three, or four FLP-binding sites altered were synthesized and labeled as for the wild-type $\chi$ structure. The $x$ structures were used to determine the effects of the site alterations on resolution by FLP protein.

When the wild-type $x$ structure was reacted with FLP protein, the two expected radioactively labeled product bands were observed (Fig. 6). The yield of these two prod- 


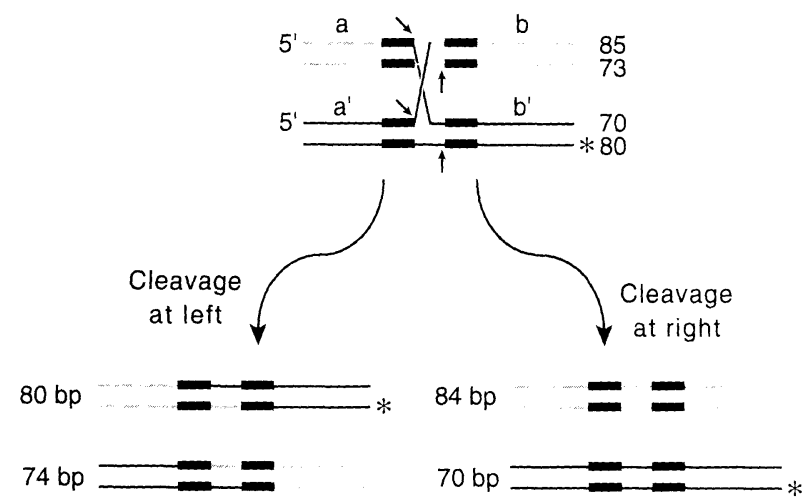

Figure 5. The wild-type $\lambda$ structure and its resolution products. Heavy bars represent the 13-bp repeats. Arrows indicate the cleavage sites. An asterisk indicates the $5^{\prime}-{ }^{32} \mathrm{P}$ label. Resolution of the $x$ structure at either the left or right side of the spacer yields the 80 - and 70-bp labeled products, respectively. Each $\chi$ structure has four FLP-binding sites, labeled $a, a^{\prime}, b$, and $b^{\prime}$.

ucts was approximately the same, indicating that the wild-type $\chi$ structures are resolved at either side of the spacer with equal probability. The majority of $\chi$ structures are resolved within $5 \mathrm{~min}$ of incubation with FLP protein at an FLP monomer/FLP-binding site ratio of 2 (Fig. 6B).

The $x$ structure with one FLP-binding site altered was resolved only at the right side of the spacer (the side distal from the altered sitel, as indicated by the appearance of only the 70-bp product (Fig. 6). The resolution efficiency of this structure, however, was comparable to that of wild-type molecules. We wished to determine whether the high level resolution of the $x$ structure with one altered FLP-binding site was an artifact of a long incubation period that obscured a much slower resolution reaction. The time course shown in Figure $6 \mathrm{~B}$ demonstrates that the kinetics of the resolution reaction with this substrate are comparable to those observed with the wild-type $\chi$. These results show that removal of one FLP-binding site does not greatly affect the $\chi$ structure resolution on the side where it retains two intact FLP-binding sites.

Previous results indicated that $x$ structures with two altered FLP-binding sites could still be resolved (Dixon and Sadowski 1993). The alterations used in the earlier study were not as extensive as ours. With the completely altered binding sites, removal of two sites had a dramatic and deleterious effect on the efficiency of resolution (Fig. $6 \mathrm{~A}, \mathrm{~B})$. The resolution that did occur was observed primarily on the right side of the spacer, where two intact FLP-binding sites (Fig. 5, b and $\mathrm{b}^{\prime}$ ) are retained. The resolution products of the reactions shown in Figure 6 were run on a denaturing gel to confirm that they were ligated fully (data not shown).

There are two other configurations for $x$ structures with two FLP-binding sites altered. We therefore looked at $\chi$ structures with FLP-binding site pairs $a b$ or $a b^{\prime}$ deleted by mutation. Both were resolved even less efficiently than when the a and a' sites were absent (Fig. 6B). When the $a$ and $b$ sites were absent, small amounts of $a$ possible deletion product were generated at rates substantially less than that shown in the generation of products from the $\chi$ structure modified at a and $\mathrm{a}^{\prime}$. As shown in Figure 7, the apparent deletion product observed mi-
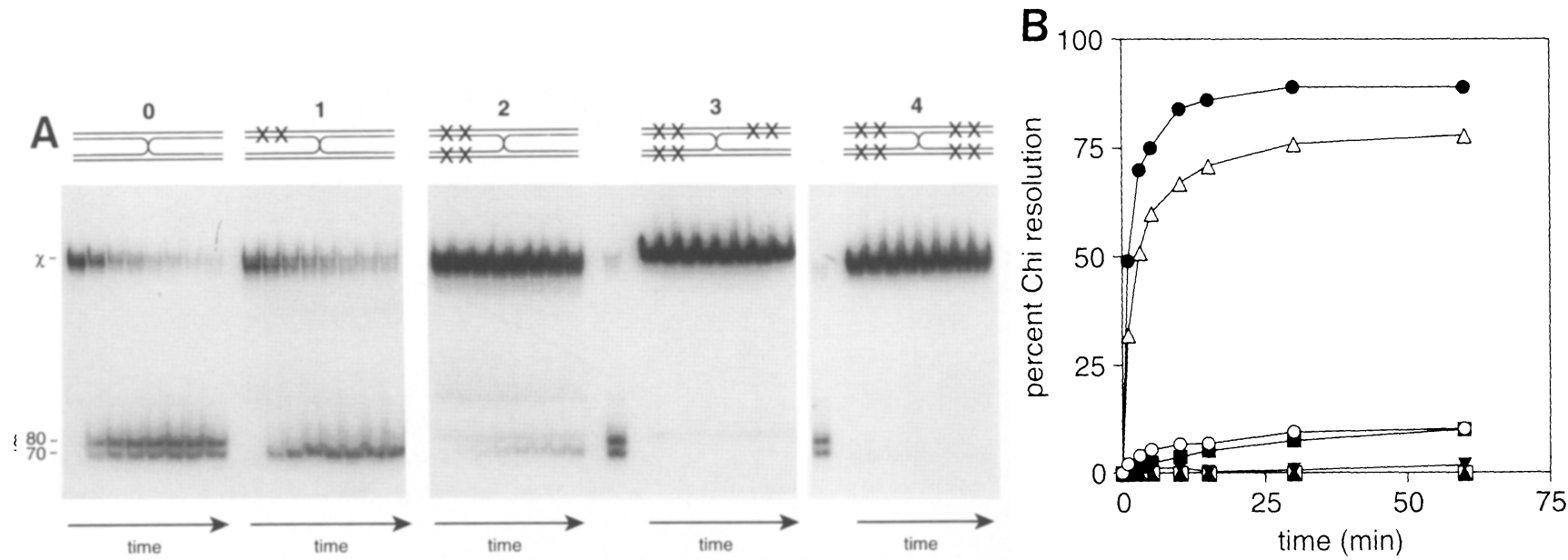

Figure 6. Resolution of $\chi$ structures. $(A)$ FLP reaction time courses for different $\chi$ structures. Lanes from left to right are aliquots taken $0,1,3,5,10,15,30$, and $60 \mathrm{~min}$ after addition of FLP protein, respectively. The numbers above the reaction sets indicate the number of FLP-binding sites that have been deleted through mutation, and the diagrams indicate which FLP-binding sites are affected (XX). All diagrams have sites oriented as in Fig. 5. The FLP protein and DNA concentrations in all reactions are 39 and $4.9 \mathrm{~nm}$, respectively. Because there are four FLP-binding sites per $\chi$ structure, the ratio of FLP protein to its binding sites is $\sim 2: 1$ for the wild-type substrate. $(B)$ Quantitation of $\chi$ resolution products. Data from gels as in $A$ was processed further to quantitate the rate of $\chi$ resolution as described in Materials and methods. The letters in the key indicate the FLP-binding sites that have been deleted through mutation,

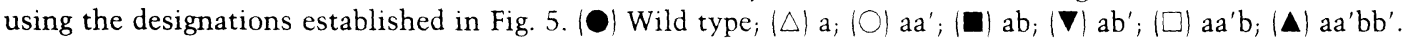




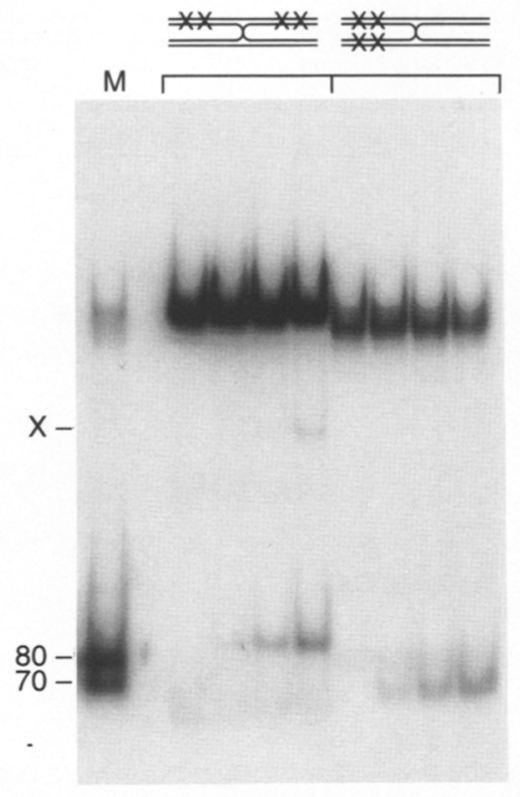

Figure 7. Resolution of $\chi$ structures containing only two intact FLP protein-binding sites. Lane $M$ contains an FLP protein reaction with a normal $\chi$ structure to provide markers for the 70 and 80 -bp resolution products. Reactions were carried out as in Fig. 6 . The four time points for each reaction were $0,5,15$, and $60 \mathrm{~min}$. The extra band $(\mathrm{X})$ observed at $60 \mathrm{~min}$, derived from the $x$ structure lacking FLP-binding sites $a$ and $b$, has not been identified.

grated slower than either of the expected products. The resolution assay used in Figures 6 and 7 includes a proteinase $\mathrm{K}$ treatment of the products. As detailed below, omitting the proteinase $\mathrm{K}$ step eliminated the generation of products with this $\chi$ structure but not those examined in Figure 6, so that the product generated in the absence of the $a$ and $b$ sites did not reflect normal and complete resolution and probably includes covalently bound FLP protein. We note that the cleavage that occurs when the $\mathrm{a}$ and $\mathrm{b}$ sites are missing is likely to reflect the trans horizontal cleavage mode. The $\chi$ structure with the a and b' sites missing did not produce a significant amount of product in the resolution assay.

When three or four FLP-binding sites were altered, no product band was detected (Fig. 6A,B). We concluded that three FLP-binding sites, but not two, are both sufficient and necessary for efficient $x$ resolution. When two FLP-binding sites were deleted, a much reduced but significant level of resolution product was obtained only when the intact FLP-binding sites were on the same side of the spacer, as the $\chi$ structure is drawn in Figure 5.

\section{FLP protein binding to $\chi$ structures}

The number of FLP protein-binding sites available does not necessarily equate to the number of FLP monomers in a complex. We wished to estimate the number of FLP monomers in complexes that were active in $\chi$ structure resolution. When FLP protein was incubated with wildtype $\chi$ structures, four new bands were observed in a gel retardation assay (labeled $\chi \mathrm{cl}, \chi \mathrm{c} 2, x \mathrm{c} 3$, and $\chi \mathrm{c} 4$ in order of fastest migration; Fig. 8). As reported previously (Dixon and Sadowski 1993), these can be attributed to the binding of one, two, three, or four FLP protein monomers to FLP-binding sites on the $x$ structure. ProteinDNA complexes formed by FLP protein binding to the linear products of resolution were also present $(\mathrm{lcl}$ and lc2). Two additional and slowly migrating bands observed when high FLP concentrations were combined with the normal $\chi$ structure were not identified.

FLP protein binding to a $\chi$ structure with one altered FLP-binding site generates two major bands, $\chi \mathrm{c} 2$ and $\chi \mathrm{c} 3$, that comigrate with the complexes we attribute to a complex with two or three FLP monomers, respectively. At very high protein concentrations, a weak band corresponding to $x \mathrm{c} 4$ was also observed. Resolution products were observed in abundance at FLP concentrations of

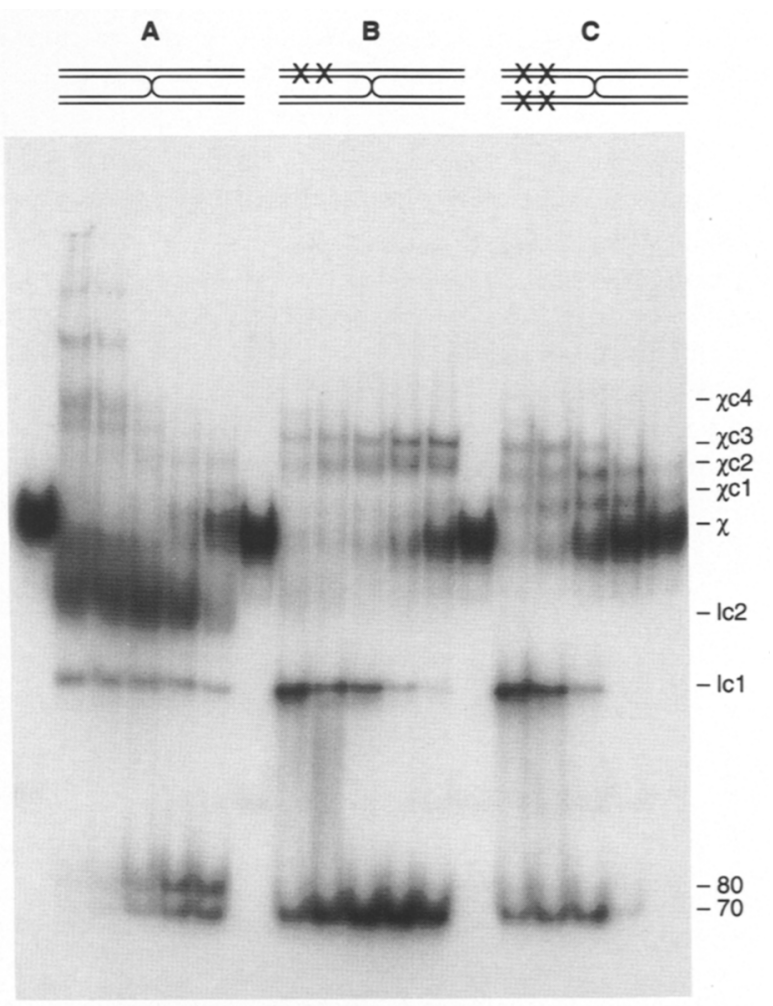

Figure 8. Gel retardation assays. Wild-type FLP protein was bound to the indicated $\chi$ structures. Protein concentrations are $0,390,195,98,39$, and $20 \mathrm{nM}$ in each set of lanes from left to right. $\chi \mathrm{cl}-\chi \mathrm{c} 4$ are complexes formed by the binding of one, two, three, and four FLP monomers to $\chi$ structures, respectively. lc 1 and lc2 are complexes formed by binding one or two FLP monomers to the linear resolution products, respectively. The two linear products are 70 and $80 \mathrm{bp}$, respectively (see Fig. 5). In the reactions with the $\chi$ structure with one arm mutated $(B)$, the $\chi c 2$ complexes run as a doublet. This is presumably because the two alternative forms of this complex have slightly different mobilities. 
Qian and Cox

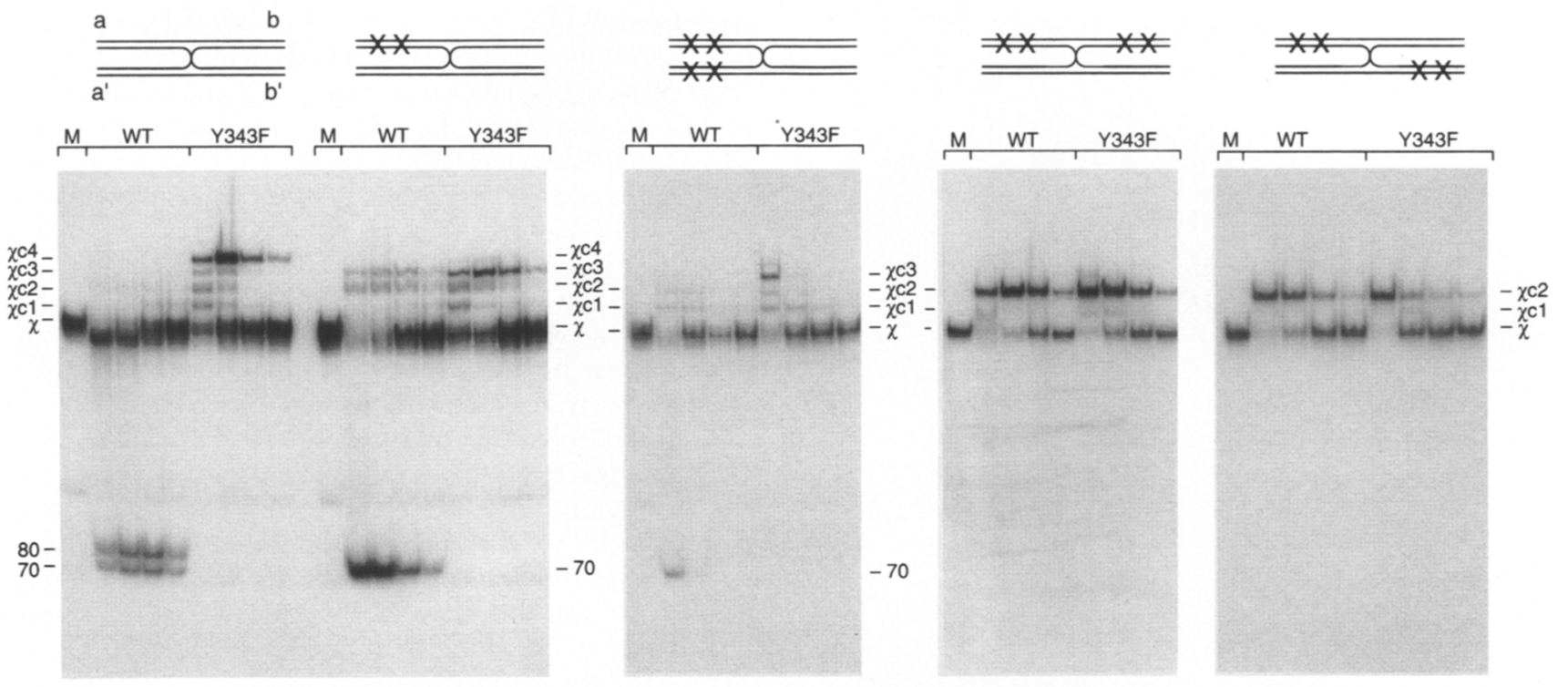

Figure 9. Mutant FLP protein (Y343F) binding to $\chi$ structures. The $\chi$ structures indicated were reacted with either wild-type (WT) or mutant $(Y 343 F)$ FLP protein. The first lane in each set is a control without protein. Protein concentrations in the remaining lanes of each set are 78,39,20, and $10 \mathrm{~nm}$ wild-type FLP protein, and 78,39,20, and $10 \mathrm{~nm}$ mutant FLP protein from left to right. Symbols and the $\chi$ structure diagrams are as in Figs. $6-8$. In the reactions with the $\chi$ structure with one arm mutated, the $\chi c 2$ complexes run as a doublet as explained in the legend to Fig. 8.

less than one-quarter of that required to generate a detectable amount of $\chi \mathrm{c} 4$.

FLP protein was also bound to $\chi$ structures with two altered FLP-binding sites. At relatively low FLP protein concentrations, the two fastest migrating complexes, $x \mathrm{c} 1$ and $x \mathrm{c} 2$, are observed, but no resolution occurs. At high protein concentrations, $x \mathrm{c} 3$ was also formed. Notably, the resolution products also appeared at higher con- centrations of FLP protein. The strongest correlation evident is that between resolution and the appearance of complex $x \mathrm{c} 3$.

It is possible that the resolution of $\chi$ structures could affect the generation of bound complexes in the experiment shown in Figure 8. We therefore examined the accumulation of FLP protein/ $\chi$ structure complexes while blocking $x$ structure resolution. Mutant FLP protein
Figure 10. SDS-resistant complexes of FLP protein with $\chi$ structures. FLP protein was reacted with the indicated $X$ structures. Reactions were carried out as in Fig. 6 , except that they were stopped by the addition of SDS only, as described in Materials and methods. Samples were run in an $8 \%(A)$ or $5 \%(B)$ polyacrylamide gel in a buffer (pH 10.1 ) containing $1.44 \%$ glycine, $25 \mathrm{~mm}$ Tris base, and $0.1 \%$ SDS. Gels were run at $25^{\circ} \mathrm{C}$ at $120 \mathrm{~V}$ for $2.25 \mathrm{hr}$. Concentrations of FLP protein and $\chi$ structures were 39 and $4.9 \mathrm{nM}$, respectively. The reactions in $A$ and $B$ show time points at 0 , $1,3,5,10,15,30$, and $60 \mathrm{~min}$ from left to right.
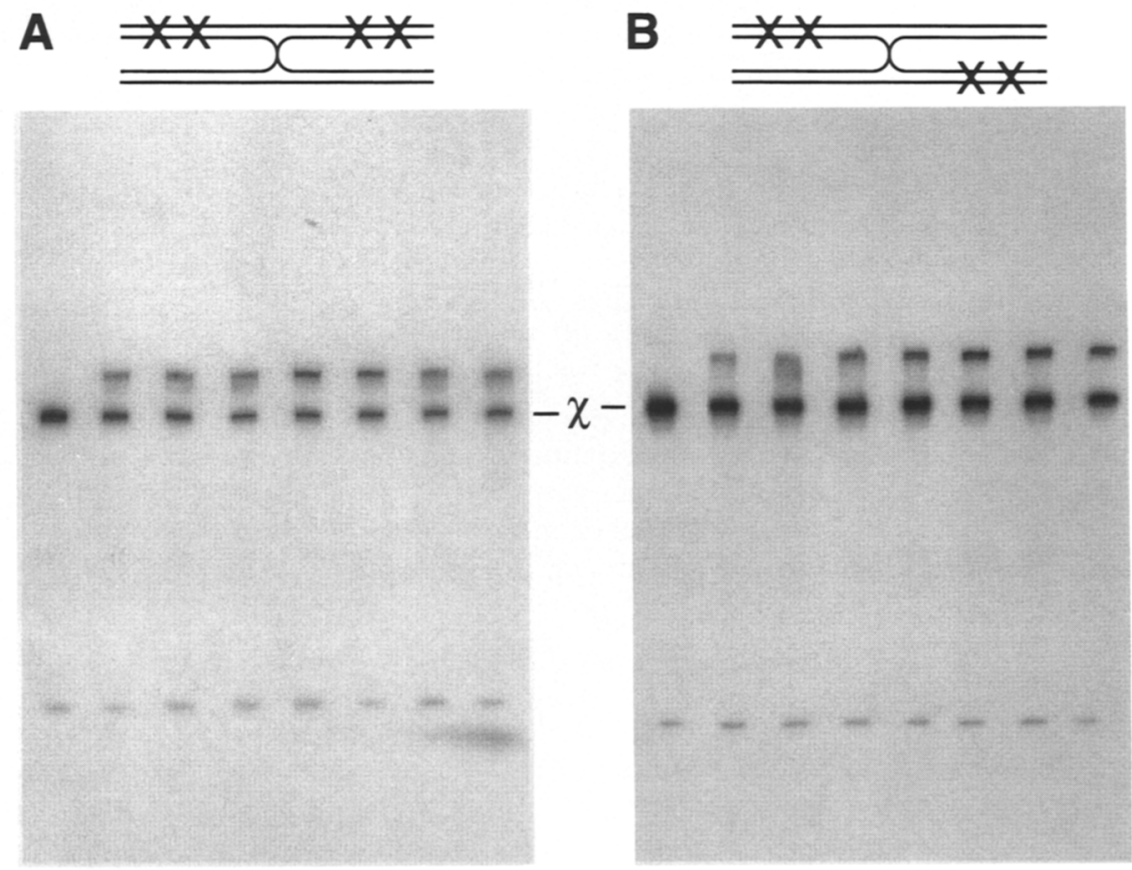


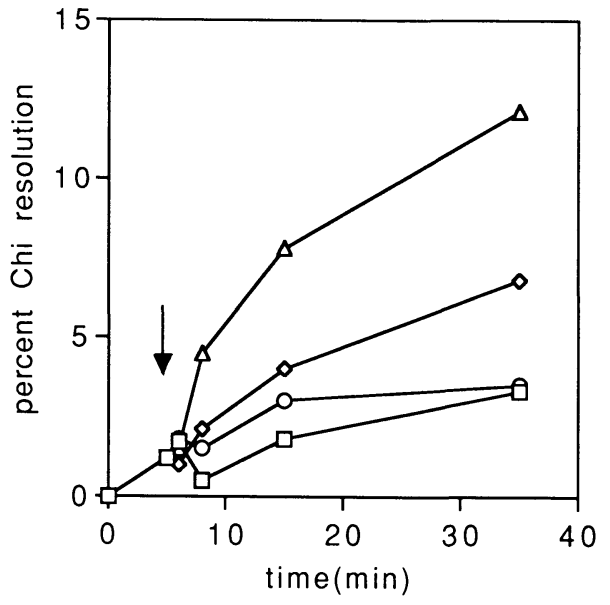

Figure 11. Inability of mutant FLP proteins to substitute for wild-type FLP in resolving altered $\chi$ structures. Resolution reactions were carried out as described in Materials and methods. Substrate $\chi$ structures $\left(4.9 \mathrm{nM}\right.$ ) with two FLP-binding sites ( $\mathrm{aa}^{\prime}$; see Fig. 5 for designations) were preincubated with 39 nM FLP protein in $200 \mu \mathrm{l}$ of reaction buffer for $5 \mathrm{~min}$. An aliquot was taken at this time to monitor the reaction, and the remaining solution was distributed into four $40-\mu l$ portions. Each portion was mixed with an equal volume of reaction buffer (minus $x$ structures) containing $78 \mathrm{nM}$ of FLP protein $(\Delta), 78 \mathrm{nM}$ of mutant $\operatorname{FLP}(\mathrm{Y} 343 \mathrm{~F})(\diamond), 78 \mathrm{nM}$ of mutant FLP (Y343F, H305S) (D), or no FLP protein (O). Aliquots were taken at $1,3,10$, and 30 min after mixing. The arrow indicates the time point of mixing.

(Y343F) was used in the binding assay, which binds to the FRT site normally but cannot cleave DNA (Evans et al. 1990). Binding of this protein to $x$ structure with one altered FLP-binding site, as shown in Figure 9, results in accumulation of complex $x \mathrm{c} 3$. Little $\chi \mathrm{c} 4$ was formed in this reaction. When binding to the wild-type $\chi$ structure, the mutant FLP protein forms predominantly $x \mathrm{cc} 4 \mathrm{com}$ plex. For mutant FLP protein binding to $\chi$ structure with two altered FLP-binding sites $\left(a\right.$ and $\left.a^{\prime}\right)$, complex $\chi c 3$ is formed only at high protein concentrations (Fig. 9). For the $\chi$ structures with two different FLP-binding sites altered, either $a$ and $b$ or $a$ and $b^{\prime}$, only complexes $\chi c l$ and $x \mathrm{c} 2$ are formed. Clearly, blockage of the DNA cleavage with the Y343F mutation successfully traps the higher order protein complexes, as evident for the wild-type $x$ structure. In this respect, the highest order stable FLP protein complex that a $\chi$ structure with one altered FLPbinding site can form is a trimer. Formation of a trimeric complex apparently does not exclude binding of a fourth protein if the corresponding wild-type FLP-binding site is available. The results suggest that the minimal active FLP protein complex is one containing three FLP monomers.

Reactions with wild-type FLP protein are included in Figure 9 for comparison. The formation of resolution products is again seen to correspond to the formation of $x \mathrm{c} 3$ complexes in the gel retardation assay. The $x$ structures with FLP-binding sites $a$ and $b$ or $a$ and $b^{\prime}$ do not yield resolution products in this assay (which does not include either proteinase or SDS), and neither one forms complexes with the mutant FLP protein of higher order than $x \mathrm{c} 2$.

The lack of resolution products for the $x$ structure missing sites $a$ and $b$ suggests that the products shown in Figure 7 reflect proteinase $\mathrm{K}$ digestion of a protein-DNA covalent complex. This is confirmed in Figure 10. When complexes of this $x$ structure and wild-type FLP protein were treated with SDS only, $\sim 40 \%$ of the DNA was found in a species that migrated slower on the gel (Fig. 10A). As shown in Figure 7, this species is eliminated by proteinase $\mathrm{K}$ treatment. With the $\chi$ structure missing sites $a$ and $b^{\prime}, \sim 30 \%$ of the DNA was converted to a

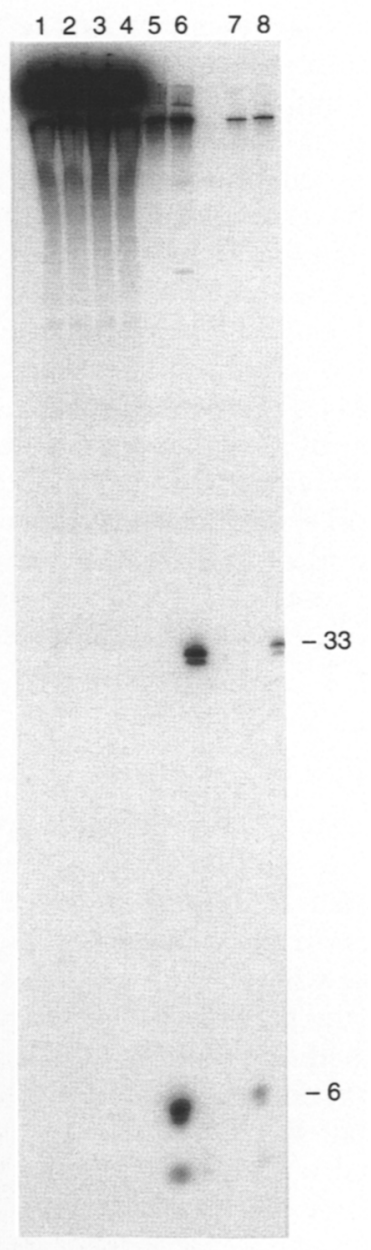

Figure 12. Determination of half-site cleavage in reactions of half-sites with full sites. The EcoRI-cut, $3^{\prime}-\left[\alpha^{-32} \mathrm{P}\right] \mathrm{dATP}$-labeled half-site (see Fig. 3 ) was reacted with PstI-cut pIFS39 full site. Each DNA substrate was present at $5.4 \mathrm{nM}$, and FLP protein concentrations were $85 \mathrm{nM}$. Lanes 1 and 2 are half-site times full-site reactions. Lanes 3 and 4 are reactions with half-sites alone. Lanes 5 and 6 are DNA size markers generated by $X b a I$ and $B a m H I$ restriction digestion of the labeled half-site DNA, respectively. The sizes of these markers in nucleotides are indicated by the numbers at the right. The amount of DNA in lanes 5 and 6 is the same as the amount of half-site DNA in lanes 1-4. The same markers are in lanes 7 and 8 , but the amount loaded is reduced 10 -fold. 
similar covalent protein-DNA complex (Fig. 10B). This SDS-resistant complex was formed at much lower levels or not at all when any of the $\chi$ structures examined in Figure 6 were tested (data not shown).

\section{Exploring the role of the third FLP monomer}

The third FLP monomer might play an auxiliary role in the resolution reaction, or it may be directly involved in the sense that it contributes some portion of the active sites. To distinguish between these possibilities, a stable $x$ c2 complex ( $x$ structure bound by two FLP monomers) was preformed by incubating wild-type FLP protein with $x$ structures containing only two FLP-binding sites. Although resolution of this $\chi$ structure is relatively weak, it is stimulated significantly by the addition of more wild-type FLP protein (Fig. 11). If the third FLP monomer plays only an auxiliary role in the reaction, mutant FLP proteins might substitute for the wild-type protein in this stimulation effect. As shown in Figure 11, FLP mutants, in which either the active site tyrosine or both the tyrosine and histidine 305 are mutated, do not substitute for the wild-type protein. Addition of mutant FLP (Y343F), which can still contribute the RHR triad active site residues, has a much reduced effect. Addition of the mutant FLP (Y343F, H305S) inhibits the reaction as compared to a control in which only buffer was added. The results suggest that the third FLP monomer plays a direct role in the resolution reaction, although we cannot eliminate the possibility that some of the inhibition caused by the mutant proteins is caused by substitution of mutant for wild-type protein at unmutated FLP-binding sites.

\section{Reaction of a full FRT site with a singular half-site}

Because only three FLP monomers appear to be necessary to carry out the two cleavage and strand exchange reactions needed to resolve a Holliday structure, we tested whether this held true for Holliday structure generation. To test whether a single half-site can react with full FRT site, the plasmid pXHQ01 was cut with EcoRI to generate a half-site with an 8-bp spacer segment that precludes formation of a head-to-head pseudo-full site (Fig. 3). This half-site was $3^{\prime}$ end labeled. When this molecule is reacted with a full site, only three FLP-binding sites are available. No strand exchange is observed with these substrates (Qian et al. 1992; data not shown). However, cleavage of the half-site may occur and should be readily detectable. As shown in Figure 12, no half-site cleavage product was detected in the reaction. Lengthening the half-site so that nonspecific DNA was available on the opposite side of the spacer sequence to bind to FLP protein did not affect the result in reactions with normal full sites. No strand exchange was observed /data not shown). As a control, the reaction of the full site with itself proceeded efficiently in the same reaction mixture (data not shown). In contrast, an $\mathrm{XbaI}$-cut halfsite (which is capable of dimerizing to form a pseudo-full site), can be cleaved either in a reaction alone or in a reaction with a full site, as reported previously (Qian et al. 1992; Chen et al. 1993). The results indicate that four FLP monomers bound to their specific recognition sequences are required for Holliday structure generation.

\section{Discussion}

In this study we define a novel aspect of the inherent asymmetry in FLP protein complexes that carry out sitespecific recombination. Three FLP monomers bound to their cognate binding sites are necessary and sufficient for the DNA cleavage and strand exchange steps that resolve a $\chi$ structure intermediate. The results are similar to those obtained for the $\lambda$ integrase by Landy and colleagues (Franz and Landy 1990). In addition, in stable trimeric complexes formed with FLP protein and halfFRT sites, two of three available half-sites are cleaved. These results contrast with the defined requirements in the reactions that generate a $\chi$ structure, where four FLP monomers bound to their cognate binding sites are needed.

If the fundamental catalytic unit of FLP recombinase is a tetramer arranged as a cooperative dimer of dimers, as the results obtained for $\chi$ structure generation suggest, then a fourth FLP monomer, bound nonspecifically and difficult to detect, may play either a direct or auxiliary role in $\chi$ structure resolution. Here, we present and discuss an alternative hypothesis that a trimeric assembly of FLP monomers represents a key catalytic unit in FLPmediated reactions.

Taken alone, the results of this study (exclusive of Fig. 11) are consistent with several modes of cleavage and strand exchange. Cleavage could occur in cis, with a third FLP monomer playing an auxiliary function, as proposed for the $\lambda$ integrase (Nunes-Düby et al. 1994). The results are also consistent with a trans-vertical cleavage pattern, again with the third FLP monomer playing an auxiliary role. The results of Figure 11 argue for a direct role for the third FLP monomer and against an auxiliary role. The overall results of the study are even more difficult to reconcile with mechanisms for cleavage requiring the close cooperation of four FLP monomers, such as the trans-horizontal or trans-diagonal modes (Fig. 2).

However, the results must be viewed in the context of a series of results from Jayaram and colleagues that demonstrate a trans-cleavage mechanism for FLP. Chen et al. (1992) observed a trans cleavage of a half-site in a reaction with full sites that indicated a trans-diagonal cleavage pattern. The trans-cleavage idea was augmented in a subsequent series of reports (Chen et al. 1993; Lee and Jayaram 1993), and its advantages described (Jayaram 1994), although other cleavage modes such as trans-horizontal were not ruled out. A more recent study is most consistent with a trans-horizontal cleavage (Lee et al. 1994). The trans-horizontal and trans-diagonal cleavage patterns are difficult to reconcile with the apparent requirement for three tightly bound FLP monomers to resolve a Holliday intermediate. If four FLP monomers participate in $\chi$ structure resolution arranged in trans-horizontal pairs, one of the FLP monomers contributing an 
active site tyrosine can be bound nonspecifically and too weakly to be readily detected in a gel retardation assay.

In Figures 2D and 13, we outline a hypothesis not yet considered for these reactions, an asymmetric cleavage mechanism in which three FLP monomers, rather than two or four, are required to form two composite active sites for cleavage. The FLP-binding sites in the FRT are symmetrical. Barring multiple DNA-binding modes, two FLP monomers should bind to the FRT to create a complex with C2 symmetry. Interaction between the two FLP monomers leads to DNA bending, as characterized

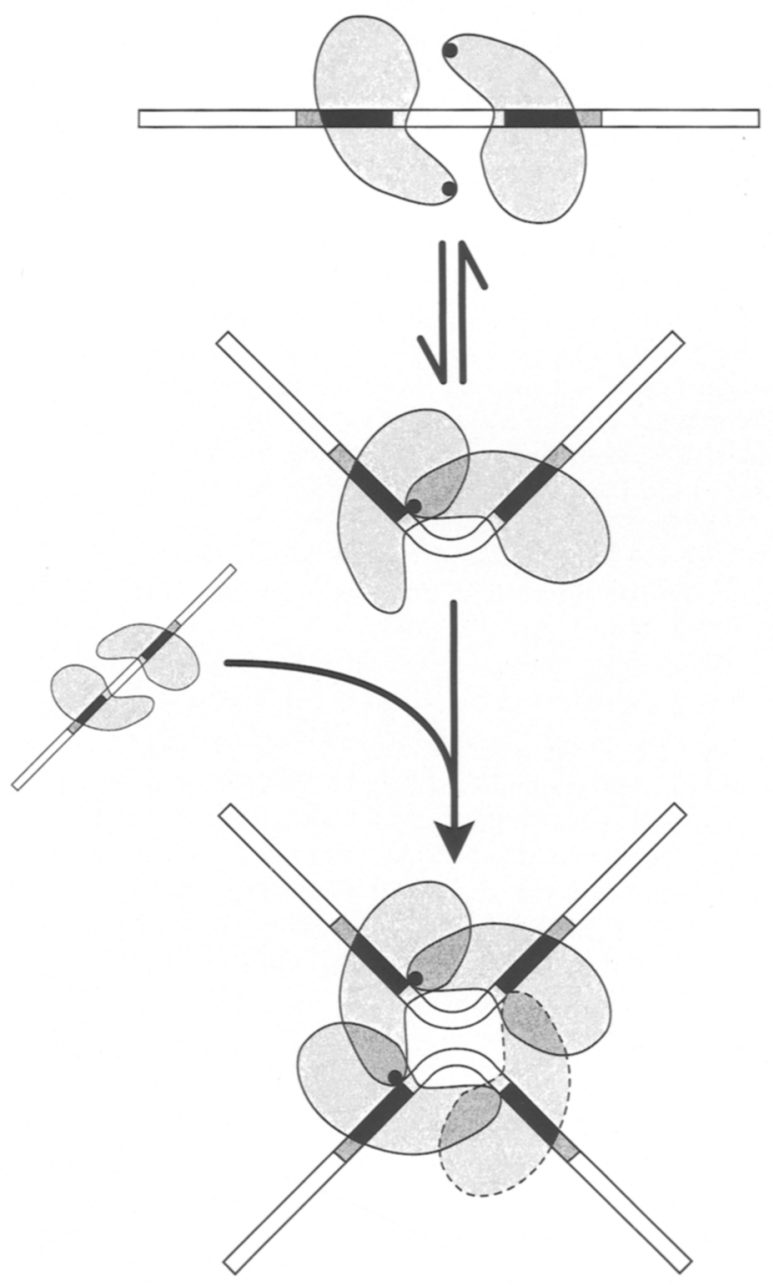

Figure 13. A model for DNA cleavage by an asymmetric trimer of FLP protein. Binding to the FRT is initially symmetric, but realignment of the complex coupled to the DNA bending characterized previously by Sadowski and colleagues (Schwartz and Sadowski 1990; Kulpa et al. 1993/ moves only one of the two FLP monomers into a position with its active site tyrosine poised for transesterification. Only one of two FLP monomers bound to the second FRT site participates in the initial cleavage and strand exchange. The illustration shows how three FLP monomers might combine to form two composite active sites for DNA cleavage and is not intended to represent the only possible scheme consistent with a trimeric catalytic FLP complex. Other geometric arrangements of the FLP monomers and DNA are possible. by Sadowski and colleagues (Schwartz and Sadowski 1990; Kulpa et al. 1993). Although an asymmetric complex could be produced in a variety of ways, the DNA bending provides a simple path to generate an asymmetric complex in which only one of the two FLP monomers had its active site tyrosine positioned to react. The other FLP monomer could participate in an intermolecular cleavage. This mechanism might yield both a trans-horizontal and a trans-vertical cleavage pattern in appropriate experiments (Fig. 2), helping to explain the sometimes conflicting results obtained with FLP. The third FLP monomer is not auxiliary but plays a direct role in the reaction. The trimeric species that we observe in the present study are very stable, and the formation of a complex containing three FLP monomers clearly correlates with cleavage and strand exchange. Even in this mechanism, a fourth monomer might play a transient auxiliary role in the reaction.

Dixon and Sadowski (1993) examined the resolution of $x$ structures, concluding that only two intact FLP protein-binding sites were required for resolution to occur. This was true regardless of which two FLP protein-binding sites were unaltered. Because resolution would presumably require two FLP monomers bound on the same side of the two FRT spacer sequences, some of the cleavage patterns suggested that at least one additional FLP monomer might bind nonspecifically to altered $x$ structures. In our work the large difference in resolution efficiency observed when more than one FLP-binding site is altered has been made more apparent. The alterations that we have made to the FLP-binding sites are complete (in the sense that the mutant site represents the most deleterious change at every base pair), and the use of detailed time courses further highlights the differences between $\chi$ structures with two or three FLP-binding sites.

The gel retardation studies provide data that emphasize a potential role for three FLP monomers in the resolution reaction. Trimeric species are observed in some cases even with $\chi$ structures that force one FLP monomer to bind nonspecifically. The minimal resolution that occurs in $x$ structures with two FLP-binding sites removed correlates closely with the observed formation of the $x \mathrm{c} 3$ (trimeric) complexes in the gel retardation experiments. In $\chi$ structures with only one FLP-binding site removed, there is little or no formation of tetrameric species, even though resolution occurs efficiently. At a minimum, the facile formation of stable trimeric species in FLP-mediated reactions suggests a new aspect of asymmetry in FLP complexes, such that any tetrameric species might be thought of as trimer plus monomer rather than dimer plus dimer.

If a fourth FLP monomer, bound nonspecifically, participates directly in $\chi$ structure resolution, the relaxation of the DNA-binding requirements would be unique to the resolution reaction. Although three FLP monomers bound to their cognate binding sites is sufficient for $\chi$ resolution, four FLP monomers thus bound are required for $\chi$ generation (presumably arranged as two dimers on separate FRT sites). Dixon and Sadowski (1993) also 
pointed out that alterations in an FLP-binding site in one of two FRT sites undergoing a reaction have a much larger effect than the same alterations in one FLP-binding site have on $\chi$ resolution. Both here (Fig. 12) and in previous work, we have noted that a reaction of half-sites with full sites does not occur unless the half-sites have ends that permit head-to-head alignment to form a pseudo-full site. In addition, two full sites do not react if one of the FLP-binding sites in one FRT is mutated so it will not bind FLP recombinase.

The idea that the fundamental catalytic unit of FLP recombinase is a trimer must be reconciled with the requirement for four specifically bound FLP monomers in $x$ generation. The fourth monomer required to initiate recombination could be needed at the synapsis step, dissociating once synapsis was complete and an active trimer had been formed. A fourth FLP monomer might also be required in the $\chi$ isomerization step, either binding transiently in a facilitation role or binding such that another FLP monomer is displaced once isomerization is complete. The latter complex reorganization would mean that $\chi$ structure formation and resolution would be carried out by trimeric FLP complexes containing a somewhat different set of FLP monomers. It is likely that FLP monomers have multiple surfaces for interaction with other monomers, with only a subset of these surfaces occupied in any given complex.

The presence of the dimeric complex in the half-site reaction may be informative. The dimer and trimer complexes are not interconvertible if they are preformed, as observed previously by Qian et al. (1990). There is no evidence that either complex is derived from the other. There are at least two scenarios for the formation of the stable dimeric complex of FLP proteins bound to halfsites: One is that the dimer is sufficient to carry out the cleavage reaction; and the other is that two dimers must come together to generate the cleaved complex. The dimers and/or trimers may be derived from a transient tetrameric species that reorganizes as soon as it is formed. The disruption of dimer formation by longer spacer sequences (Qian et al. 1990) provides evidence that the cleavage within the half-site dimers is effectively trans-horizontal.

The recent work of Landy and co-workers (NunesDüby et al. 1994) indicates that cleavage by the $\lambda$ integrase occurs in cis. This contrasts with FLP and provides the first indication that the reaction mechanisms in the two systems are significantly different. We note, however, that the complementation studies of Han et al. (1993) indicated that a composite active site can be formed in reactions of the $\lambda$ integrase as demonstrated for FLP protein. There is also evidence that three Int monomers are needed to promote cleavage and strand exchange (Franz and Landy 1990; Kho and Landy 1994). A slight modification of the composite active site model proposed by Jayaram for FLP may be worth some consideration for the $\lambda$ integrase. One could imagine a situation in which the nucleophylic tyrosine provided by the Int monomer bound adjacent to the cleavage site (in cis) was complemented by RHR catalytic residues provided by an
Int monomer bound elsewhere (in trans). If a composite active site of this kind were possible, the results of Han et al. (1993) and Nunes-Düby et al. (1994) might be reconciled, and a plausible asymmetric trimer model similar to the model in Figure 2D might be constructed for Int.

\section{Materials and methods}

\section{Enzymes and chemical reagents}

FLP protein was purified by a published procedure (Pan et al. 1991), with the exception that the preparations were applied to an FRT DNA affinity column (Meyer-Leon et al. 1987) before the FPLC Mono-S cation exchange step. FLP protein obtained in this manner is $>95 \%$ homogenous as determined by SDSPAGE. The FLP protein concentration was determined using the method of Bradford (1976). Mutant FLP proteins (a single mutant, Y343F, and a double mutant, Y343F, H305S) were generous gifts from M. Jayaram (University of Texas, Austin). The mutant proteins were purified further by chromatography on a DNA affinity column (Meyer-Leon et al. 1987) to $>80 \%$ purity as determined by SDS-PAGE. The concentration of mutant proteins was measured on a polyacrylamide gel after Coomassie staining, using several lanes with known wild-type FLP protein concentrations to generate a standard curve with a One-Scanner laser scanner and the Ofoto software program. Restriction enzymes, T4 polynucleotide kinase, and $\beta$-agarase I were purchased from New England Biolabs. Oligonucleotides were synthesized by Operon Technologies, Inc. Low-melting-temperature agarose (type VII) and bovine serum album were from Sigma. Syringe filters $(0.45 \mu \mathrm{m}$ pore size $)$ were from NalGene, Inc.

\section{DNA substrates}

Half-FRT site DNA was generated by XbaI or EcoRI restriction digestions of plasmid pXHQ01 (2811 bp; Qian et al. 1990). This plasmid contains a single half-FRT site, and the restriction digestion generates a linear DNA with the half-site at or near the end as shown in Figure 3. The XbaI-cut DNA was labeled at the $3^{\prime}$ end with $\left[\alpha{ }^{-32} \mathrm{P}\right] \mathrm{dCTP}$ by avian myeloblastosis virus reverse transcriptase (Qian et al. 1990). The labeling efficiencies at either end of the DNA were equal as determined by cleaving the labeled DNA with PstI and quantitation of the ${ }^{32} \mathrm{P}$ label in the resulting 0.8 and $2.0-\mathrm{kbp}$ fragments. The EcoRI-cut half-site DNA was labeled at the $3^{\prime}$ ends with $\left[\alpha^{-32} \mathrm{P}\right] \mathrm{dATP}$ using the same method. Full-site DNA was generated by PstI digestion of plasmid pJFS39 (2820 bp) (Senecoff and Cox 1986). All plasmid DNA used in this study was purified by banding twice in a cesium chloride gradient in the presence of ethidium bromide. The concentrations of single-stranded and double-stranded DNAs were determined by absorbance at $260 \mathrm{~nm}$, using 36 or 50 $\mu \mathrm{g} / \mathrm{ml}$ per $A_{260}$ unit as conversion factors, respectively. DNA concentrations are expressed in terms of total molecules.

\section{Construction of Holliday $(\chi)$ structures}

$\chi$ structures were generated by annealing four complementary oligonucleotides. The sequences of the oligonucleotides forming the wild-type $\chi$ structure are as follows /the FRT sequences are underlined, the 13-bp repeat are shown by italics, and the spacer is in bold):
1. 5'-GATCCACAGGTAACGCACTAGGTCGAAGTTCCT- ATACTTTCTAGAGAATAGGAACTTCCGACAGCCAC- TA-3' (70-mer). 
2. 5'-CGATTGACAGCTACAGAGAGAAGTTCCTATTCTCTAGAAAGTATAGGAACTTCGACCTAGTGCGTTACCTGTG-3' (73-mer).

3. 5'-TCGAGGAACTCTGCTCATAGCCAGATTCTGAGCTGAAGTTCCTATA CTTTCTAGAGAATAGGAACTTCTCTCTGTAGCTGTCAAT-3', (85-mer);

4. 5'-AGCTTAGTGGCTGTCGGAAGTTCCTATTCTCTAGAAAGTATAGGAACTTCAGCTCAGAATCTGGCTATGAGCAGAGTTCC-3' (80-mer).

The altered $x$ structures have the same sequences as the wild type except that the 13-bp repeat is replaced with 5'-GTCTCATAATAAG. When $\chi$ structures have both repeats altered at one side of the spacer, the upper repeat is replaced with the sequence of 5'-GTCTCATAATAAG and the lower repeat is replaced with a slightly different sequence of $5^{\prime}$-GTCTCATAAGAAG.

The four oligonucleotides used to form each $\chi$ structure were purified by electrophoresis in a $12 \%$ polyacrylamide gel with 8 $M$ urea. The 80-base oligonucleotide was labeled at the $5^{\prime}$ end with $\left[\gamma^{-32}\right.$ P]ATP by T4 polynucleotide kinase (Maniatis et al. 1982). About $2.7 \mu \mathrm{g}$ of this DNA and $6.3 \mu \mathrm{g}$ of the same unlabeled oligonucleotide were mixed with $9 \mu \mathrm{g}$ of each of the other three oligonucleotides in a $70-\mu$ l solution containing $100 \mathrm{mM}$ $\mathrm{NaCl}$. The mixture was heated at $70^{\circ} \mathrm{C}$ for $3 \mathrm{~min}$, then cooled slowly to room temperature. The DNA species in the annealing mixture were separated by electrophoresis in a $5 \%$ polyacrylamide gel. The slowest migrating species, corresponding to the $x$ structure, was excised from the gel. The DNA was recovered from the gel slice by soaking in $1.3 \mathrm{ml}$ of TAE buffer $(0.04 \mathrm{M}$ Tris-acetate at $\mathrm{pH} 7.4$, and $0.01 \mathrm{M}$ EDTA) overnight. The solution was then passed through a syringe filter $(0.45 \mu \mathrm{m}$ pore size). DNA was recovered by precipitation in three volumes of ethanol and one-tenth volume of $3 \mathrm{M} \mathrm{NaOAc}$.

Reactions with half-FRT sites, and determination of extent of DNA cleavage in trimeric half-site complexes

Reactions were carried out in a standard reaction mixture $(20 \mu \mathrm{l})$ containing $25 \mathrm{~mm}$ TAPS buffer at pH 8.0, $1 \mathrm{~mm}$ EDTA, 10\% (vol/vol) glycerol, $5 \%$ (wt/vol) PEG (polyethylene glycol, molecular weight 8000 ), $200 \mathrm{~mm} \mathrm{NaCl}, 5.4 \mathrm{~nm} \mathrm{XbaI-cut} \mathrm{and} \mathrm{3'-end}$ labeled half-site DNA, and 85 or 43 nM FLP protein. Reaction mixtures were incubated at $30^{\circ} \mathrm{C}$ for $10 \mathrm{~min}$. An aliquot of $10 \mu \mathrm{l}$ was loaded onto a $0.8 \%$ low-melting-temperature agarose gel, and electrophoresis was carried out at $5 \mathrm{~V} / \mathrm{cm}$ at room temperature for $70 \mathrm{~min}$ in $1 \times \mathrm{TBE}(0.089 \mathrm{M}$ Tris- $\mathrm{HCl}$ at $\mathrm{pH} 8.0,0.089$ $\mathrm{M}$ boric acid, $0.002 \mathrm{M}$ EDTA). The gel was stained in $0.5 \mathrm{\mu g} / \mathrm{ml}$ of ethidium bromide at $4^{\circ} \mathrm{C}$. The DNA band corresponding to the dimeric or trimeric complexes was cut out of the gel. The gel slice was heated in an eppendorf tube at $70^{\circ} \mathrm{C}$ for $5 \mathrm{~min}$ and transferred to $40^{\circ} \mathrm{C}$. To this melted agarose solution $(80 \mu l) 40 \mu \mathrm{l}$ of $\beta$-agarose was added $(0.2 \mathrm{U} / \mu \mathrm{l})$. This mixture was incubated at $40^{\circ} \mathrm{C}$ for $60 \mathrm{~min}$, followed by addition of $5 \mu \mathrm{l}$ of PstI $(20 \mathrm{U} / \mu \mathrm{l})$ and $13 \mu \mathrm{l}$ of NEBuffer II (New England BioLabs). After incubation of this solution at $40^{\circ} \mathrm{C}$ for $30 \mathrm{~min}, 6 \mu \mathrm{l}$ of $10 \% \mathrm{SDS}$ and 10 $\mu \mathrm{l}$ of proteinase $\mathrm{K}(20 \mathrm{mg} / \mathrm{ml})$ were added. The mixture was incubated at $37^{\circ} \mathrm{C}$ for $15 \mathrm{~min}$. Then tRNA $(2 \mu \mathrm{l}$ at $5 \mu \mathrm{g} / \mu \mathrm{l})$ was added, and DNA was recovered by ethanol $/ \mathrm{NaOAc}$ precipitation as described above. The DNA pellet was dissolved in $10 \mu \mathrm{l}$ of TE buffer. To this was added $2 \mu$ l of RNase A $(10 \mu \mathrm{g} / \mu \mathrm{l})$. The mixture was incubated at $37^{\circ} \mathrm{C}$ for $30 \mathrm{~min}$, followed by addition of $2 \mu \mathrm{l}$ of $10 \%$ SDS and $4 \mu \mathrm{l}$ of GEB buffer (30\% glycerol, $0.25 \%$ bromophenol blue). The solution was then loaded onto a $1 \%$ agarose gel. After electrophoresis (at 5 Volts $/ \mathrm{cm}$ for $60 \mathrm{~min}$ ), the gel was dried onto DE-81 paper (Whatman). The DNA was visualized by autoradiography. Two bands were cut out of the gel and quantified by liquid scintillation counting on a Beckman LS-3801 counter.

\section{$\chi$-Structure resolution reactions}

A solution (180 $\mu \mathrm{l})$ was prepared without FLP protein, containing $25 \mathrm{~mm}$ TAPS buffer (pH 8.0), $1 \mathrm{~mm}$ EDTA, $5 \%$ (vol/vol) glycerol, $200 \mathrm{mM} \mathrm{NaCl}, 0.45 \mathrm{mg} / \mathrm{ml}$ of calf thymus DNA, 2 $\mathrm{mg} / \mathrm{ml}$ of BSA, and $0.5 \mu \mathrm{g} / \mathrm{ml}$ labeled $\chi$ structure DNA $14.9 \mathrm{nM}$ in molecules). As a zero time control, an 18- $\mu$ l aliquot was removed from this solution prior to FLP protein addition. The reaction was initiated by addition of $18 \mu \mathrm{l}$ of $0.39 \mu \mathrm{M}$ FLP protein (39 $\mathrm{nM}$ final concentration in the reaction mixture) and incubated at $30^{\circ} \mathrm{C}$. Aliquots of $20 \mu \mathrm{l}$ were withdrawn at various time points. To each aliquot $2 \mu \mathrm{l}$ of $1 \%$ SDS and $2 \mu \mathrm{l}$ of proteinase $\mathrm{K}$ were added $(2 \mathrm{mg} / \mathrm{ml})$. This mixture was incubated at $37^{\circ} \mathrm{C}$ for $15 \mathrm{~min}$. In a few reactions, as noted, the proteinase $\mathrm{K}$ and the 15-min incubation were omitted. Half of this mixture was loaded onto a $5 \%$ polyacrylamide gel in $1 \times$ TBE buffer for electrophoresis at $10 \mathrm{~V} / \mathrm{cm}$ (constant power). DNA in the gel was visualized by autoradiography. The product and substrate bands were cut out and quantified by liquid scintillation counting on a Beckman LS-3801 counter. The calf thymus DNA included in the experiments was necessary to confer specificity on the reaction. In its absence, FLP protein cleaves all $\chi$ structures efficiently even when there are no FLP-binding sites present.

\section{Gel retardation assays}

Reaction conditions were identical to the $\chi$ resolution reaction except that the FLP protein concentrations were varied. Wildtype or mutant FLP protein solutions were diluted to appropriate concentrations with dilution buffer $(25 \mathrm{~mm}$ TAPS at $\mathrm{pH} 8.0$, $1 \mathrm{~mm}$ EDTA, $10 \%$ glycerol, and $1 \mathrm{M} \mathrm{NaCl}$ ). Diluted FLP protein $(3 \mu \mathrm{l})$ was added to reaction mixtures $(27 \mu \mathrm{l})$ containing all other components to initiate reaction. After incubation for $10 \mathrm{~min}$ at $30^{\circ} \mathrm{C}$, a $10-\mu$ l aliquot of each reaction mixture was removed and loaded onto a $5 \%$ polyacrylamide gel in $1 \times$ TBE. Electrophoresis was carried out at $15 \mathrm{~V} / \mathrm{cm}$ (constant voltage) at room temperature for $\sim 1.5 \mathrm{hr}$. DNA bands were visualized by autoradiography.

\section{Reaction of half-sites with full sites}

Reaction conditions for experiments combining EcoRI-cut pXHQ01 half-site DNA with PstI-cut pJFS39 full-site DNA were the standard conditions described above (with the FLP protein concentration at $85 \mathrm{nM}$ ), except that $5.4 \mathrm{nM}$ full-site DNA was also included. The reaction was stopped by boiling for 2 min and kept on ice until the sample was loaded onto a $12 \%$ denaturing-polyacrylamide gel $(8 \mathrm{M}$ urea).

\section{Acknowledgments}

We thank Lisa Iype for providing the wild-type FLP protein used in these experiments. We also thank Jehee Lee and Makkuni Jayaram for generously providing the purified FLP Y343F and Y343F, H305S mutant proteins. This work was supported by grant GM37835 from the National Institutes of Health.

The publication costs of this article were defrayed in part by payment of page charges. This article must therefore be hereby marked "advertisement" in accordance with 18 USC section 1734 solely to indicate this fact. 


\section{References}

Abremski, K.E. and R.H. Hoess. 1992. Evidence for a second conserved arginine residue in the integrase family of recombination proteins. Protein Eng. 5: 87-91.

Argos, P., A. Landy, K. Abremski, J.B. Egan, L.E. Haggard, R.H. Hoess, M.L. Kahn, B. Kalionis, S.V. Narayana, L.S. Pierson III, N. Sternberg, and J.M. Leong. 1986. The integrase family of site-specific recombinases: Regional similarities and global diversity. EMBO /. 5: 433-440.

Bradford, M.M. 1976. Anal. Biochem. 72: 248-254.

Chen, J.W., J. Lee, and M. Jayaram. 1992. DNA cleavage in trans by the active site tyrosine during Flp recombination: Switching protein partners before exchanging strands. Cell 69: 647658.

Chen, J.W., S.H. Yang, and M. Jayaram. 1993. Tests for the fractional active-site model in Flp site-specific recombination. Assembly of a functional recombination complex in half-site and full-site strand transfer. I. Biol. Chem. 268: 1441714425.

Cox, M.M. 1989. DNA inversion in the $2 \mu \mathrm{m}$ plasmid of Saccharomyces cerevisiae. In Mobile DNA, (ed. D.E. Berg and M.M. Howe), pp. 661-670. American Society for Microbiology, Washington, D.C.

Craig, N.L. 1988. The mechanism of conservative site-specific recombination. Annu. Rev. Genet. 22: 77-105.

Dixon, J.E. and P.D. Sadowski. 1993. Resolution of synthetic Chi structures by the FLP site-specific recombinase. J. Mol. Biol. 234: 522-533.

Evans, B.R., J.W. Chen, R.L. Parsons, T.K. Bauer, D.B. Teplow, and M. Jayaram. 1990. Identification of the active site tyrosine of Flp recombinase. Possible relevance of its location to the mechanism of recombination. I. Biol. Chem. 265: $18504-18510$.

Franz, B. and A. Landy. 1990. Interactions between lambda Int molecules bound to sites in the region of strand exchange are required for efficient Holliday junction resolution. I. Mol. Biol. 215: 523-535.

Han, Y.W., R.I. Gumport, and J.F. Gardner. 1993. Complementation of bacteriophage lambda integrase mutants: Evidence for an intersubunit active site. EMBO J. 12: 4577-4584.

Jayaram, M. 1994. Phosphoryl transfer in Flp recombination: A template for strand transfer mechanisms. Trends Biochem. Sci. 19: 78-82.

Kho, S.H. and A. Landy. 1994. Dissecting the resolution reaction of lambda integrase using suicide Holliday junction substrates. $E M B O$ I. 13: 2714-2724.

Kimball, A.S., J. Lee, M. Jayaram, and T.D. Tullius. 1993. Sequence-specific cleavage of DNA via nucleophilic attack of hydrogen peroxide, assisted by Flp recombinase. Biochemis try 32: 4698-4701.

Kulpa, J., J.E. Dixon, G. Pan, and P.D. Sadowski. 1993. Mutations of the FLP recombinase gene that cause a deficiency in DNA bending and strand cleavage. J. Biol. Chem. 268: 11011108.

Landy, A. 1993. Mechanistic and structural complexity in the site-specific recombination pathways of Int and FLP. Curr. Opin. Genet. and Dev. 3: 699-707.

Lee, J. and M. Jayaram. 1993. Mechanism of site-specific recombination. Logic of assembling recombinase catalytic site from fractional active sites. I. Biol. Chem. 268: 17564-17570.

Lee, J., I. Whang, J. Lee, and M. Jayaram. 1994. Directed protein replacement in recombination full-sites reveals trans-horizontal DNA cleavage by FLP recombinase. EMBO $J$. 13: 5346-5354.

Meyer-Leon, L., C.A. Gates, I.M. Attwood, E.A. Wood, and
M.M. Cox. 1987. Purification of the FLP site-specific recombinase by affinity chromatography and re-examination of basic properties of the system. Nucleic Acids Res. 15: 64696488.

Nunes-Düby, S.E., R.S. Tirumalai, L. Dorgai, E. Yagil, R.A. Weisberg, and A. Landy. 1994. $\lambda$ integrase cleaves DNA in cis. $E M B O$ I. 13: 4421-4430.

Pan, G. and P.D. Sadowski. 1992. Ligation activity of FLP recombinase. The strand ligation activity of a site-specific recombinase using an activated DNA substrate. I. Biol. Chem. 267: 12397-12399.

Pan, H., D. Clary, and P.D. Sadowski. 1991. Identification of the DNA-binding domain of the FLP recombinase. I. Biol. Chem. 266: 11347-11354.

Qian, X.H., R.B. Inman, and M.M. Cox. 1990. Protein-based asymmetry and protein-protein interactions in FLP recombinase-mediated site-specific recombination. I. Biol. Chem. 265: 21779-21788.

1992. Reactions between half- and full-FLP recombination target sites. A model system for analyzing early steps in FLP protein-mediated site-specific recombination. I. Biol. Chem. 267: 7794-7805.

Sadowski, P.D. 1993. Site-specific genetic recombination: Hops, flips, and flops. FASEB 1. 7: 760-767.

Schwartz, C.J. and P.D. Sadowski. 1990. FLP protein of $2 \mu$ circle plasmid of yeast induces multiple bends in the FLP recognition target site. I. Mol. Biol. 216: 289-298.

Senecoff, J.F. and M.M. Cox. 1986. Directionality in FLP protein-promoted site-specific recombination is mediated by DNA-DNA pairing. I. Biol. Chem. 261: 7380-7386.

Senecoff, J.F., P.J. Rossmeissl, and M.M. Cox. 1988. DNA recognition by the FLP recombinase of the yeast $2 \mathrm{mu}$ plasmid. A mutational analysis of the FLP binding site. /. Mol. Biol. 201: 405-421

Stark, W.M., M.R. Boocock, and D.J. Sherratt. 1992. Catalysis by site-specific recombinases. Trends Genet. 8: 432-439. 


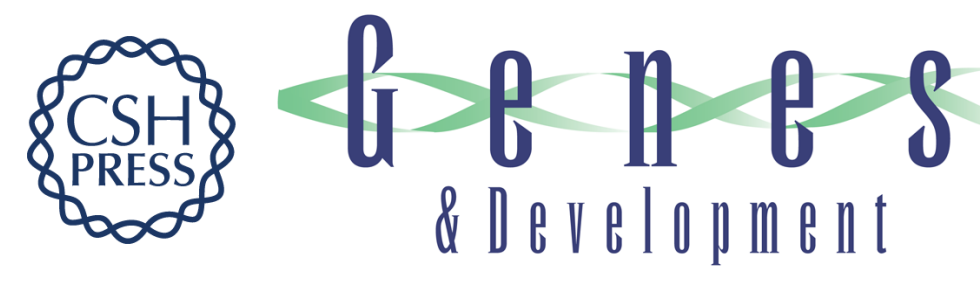

\section{Asymmetry in active complexes of FLP recombinase.}

X H Qian and M M Cox

Genes Dev. 1995, 9:

Access the most recent version at doi:10.1101/gad.9.16.2053

References This article cites 28 articles, 9 of which can be accessed free at: http://genesdev.cshlp.org/content/9/16/2053.full.html\#ref-list-1

License

Email Alerting Receive free email alerts when new articles cite this article - sign up in the box at the top Service right corner of the article or click here.

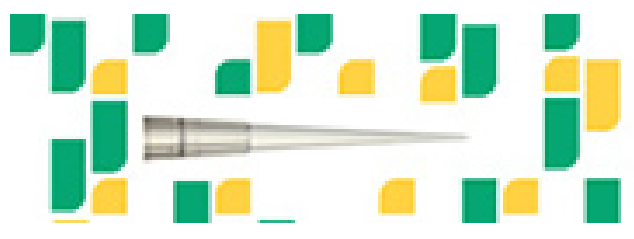

Focused on your science. 